\title{
Barriers of Condom Use among HIV Positive Women at Thika Level 5 Hospital, Kenya
}

Anne G Macharia' ${ }^{1}$, Yeri Kombe ${ }^{2}$, Peter Mwaniki ${ }^{1}$ and Michael Habtu ${ }^{3 *}$

${ }^{1}$ Institute of Tropical Medicine and Infectious Diseases, Jomo Kenyatta University of Agriculture and Technology, Nairobi, Kenya

${ }^{2}$ Center for Public Health Research, Kenya Medical Research Institute, Nairobi, Kenya

${ }^{3}$ Department of Public Health, School of Health Sciences, Mount Kenya University, Kigali Campus, Rwanda

\begin{abstract}
Human immunodeficiency virus (HIV)/Acquired immune deficiency syndrome (AIDS) is the key public health concern particularly in sub-Saharan Africa including Kenya. Consistent condom use is crucial especially among HIV positive people to prevent HIV transmission as well as re-infection with different resistant virus strain. It is important to identify the obstacles of condom use among HIV positive individuals in order to constitute preventive measures. Thus, the study was conducted to explore barriers and challenges of condom use among women living with HIV attending Comprehensive Care Centre of Thika Level 5 Hospital, Kenya. We conducted qualitative method of data collection using three focus group discussions and ten key informant interviews. Purposive sampling was used to select participants. Descriptive quotes representing key themes were identified and then analysed thematically. The result indicated that the main barriers of condom use were inability to negotiate in condom use, fear of mistrust, nondisclosure of HIV positive status to partner, alcohol use, and reduced sexual pleasure. In addition, among the negative beliefs and misconceptions identified as barriers of condom use were feeling promiscuous for carrying condoms, religion (being Catholic) and perceived pores in condoms. HIV positive women face many challenges in using condoms and the specific areas of focus should include the barriers mentioned above.
\end{abstract}

Keywords: Barriers; Condom use; HIV positive women; HIV status

\section{Introduction}

HIV/AIDS remains a major public health and development problem. By the end of 2012 there were about 35.3 million HIV positive people worldwide [1]. About two thirds (68\%) of all people living with HIV worldwide are living in sub-Saharan Africa (SSA) among which $59 \%$ are women. Nearly 1.9 million new infections were reported in SSA in 2010, representing more than two-thirds (70\%) of all new infections globally [2].

In Kenya the number of people living with HIV was 1.5 million in 2015. The number of deaths from AIDS related illnesses in Kenya is still high for example it was approximately 36,000 deaths in 2015 [3]. Moreover, in Kenya the proportion of women living with HIV is disproportionately more (7.6\%) compared to men (5.6\%) in 2014 [4].

Mortality and morbidity from HIV/AIDS have reduced with the advent of antiretroviral treatment and now people with HIV are living longer and healthier $[5,6]$. However, there is a concern regarding HIV transmission to other sero-negative individuals and acquiring drug resistant viral strains from HIV infected people if condoms are not used during sex [7-10]. It is always recommended to use condom consistently [11], though there is low risk of HIV transmission through sexual contact from people who are on ART unless other sexually transmitted infections are present [12-14]. Any reduction in the capacity of HIV to replicate is likely to reduce the risk of HIV transmission $[13,14]$.

There is evidence that condoms remain one of the most cost effective tools available in HIV prevention [15,16]. Nonetheless, condom use has not received enough attention among HIV positive people when compared to HIV negative people. HIV programs always focus on prevention of HIV among uninfected people $[17,18]$. Therefore, information on condom use among HIV positive people is paramount to prevent the transmission of HIV to sero-negative sexual partners as well as preventing reinfections with different strains $[19,20]$.

In spite of the recognition that condoms are among the most important weapons in the fight of HIV/AIDS, there is little qualitative information regarding barriers of condom use among HIV positive people. The aim of this study was therefore to explore the barriers of condom use among HIV positive women at Comprehensive Care Centre of Thika Level 5 Hospital, Kenya.

\section{Materials and Methods}

\section{Study setting}

The study was conducted at the Comprehensive Care Center (CCC) of Thika Level 5 Hospital. It is located at the heart of Thika Town of Kiambu County which is about 40 kilometers North East of Nairobi city. It provides health services to an average of 20,000 inpatients and 350,000 outpatients annually to a catchment population of 3-5 Million people on average. It has a comprehensive care center wing that handles HIV/AIDS patients, dispensing medicine and counseling.

\section{Study design and population}

The study used qualitative data collection approach. Three focus group discussions (FGDs) and 10 key informant interviews (KIIs) were used. Eligible participants were 34 HIV positive women between the ages of 18 and 49 years and those who were able to provide informed consent. A focus group discussion is a way of gathering people together from similar backgrounds or experiences to discuss on a defined area

*Corresponding author: Michael Habtu, Department of Public Health, Schoo of Health Sciences, Mount Kenya University, Kigali Campus, Rwanda; Tel: 250784460645; E-mail: mikel.habtu@yahoo.com

Received July 21, 2017; Accepted August 09, 2017; Published August 16, 2017

Citation: Macharia AG, Kombe Y, Mwaniki P, Habtu M (2017) Barriers of Condom Use among HIV Positive Women at Thika Level 5 Hospital, Kenya. J AIDS Clin Res 8: 722. doi: 10.4172/2155-6113.1000722

Copyright: (c) 2017 Macharia AG, et al. This is an open-access article distributed under the terms of the Creative Commons Attribution License, which permits unrestricted use, distribution, and reproduction in any medium, provided the original author and source are credited. 
of interest. Key informant interview is a conversation with one person in which the participant is encouraged to talk in depth about the topic under investigation without the researcher's use of predetermined, focused, short-answer questions.

\section{Sample size and technique}

Three FGDs and ten KIIs were conducted. Each FGD was consisted of 8 participants. The twenty (24) participants for the FGDs and ten (10) for the KIIs were selected purposively. Purposive sampling is a non-probability sampling method also known as 'judgmental sampling' that is used to select participants based on the researchers personal judgment about which ones will be most representative or informative.

\section{Focus group discussions (FGDs)}

An FGD guide was developed and it was mainly concerned about perceptions and use of condoms among HIV positive women. The discussions were conducted by the principal investigator, who acted as the moderator and a second person to record (both females). A tape recorder was used to capture all data from the groups. Participants were selected based on age (18-24 years, 25-32 years and 33-49 years). The discussions were conducted in the counseling room in the CCC clinic which offered a quiet and conducive environment. A written informed consent was obtained from each participant.

\section{Key informant interviews (KIIs)}

Key informant interviews (KIIs) were used to gather data on experiences with condom use. It was developed to guide the interviews. This approach was useful to capture insights that would otherwise be difficult to voice in gatherings of people (FGDs). Ten participants were selected based on age and female sex. The interviews were conducted by the researcher at the same venue as FGDs. After written informed consent was obtained, a voice recorder was used to collect the data.

\section{Analysis}

All transcripts were read though and codes generated. Responses with similar codes were re-categorized under unifying sub-themes or theme. A matrix was created and individual matrices were reviewed until an agreement is reached. The categories were then interpreted for their descriptive meaning. Descriptive quotes representing key themes were identified and included in the final report writing.

\section{Ethical considerations}

Ethical clearance was sought and obtained from Kenya Medical Research Institute (KEMRI), Ethical Review Committee. All study participants consented after a detailed explanation of the purpose of the study was given.

\section{Results and Discussion}

\section{Socio demographic characteristics}

Demographic information on the 34 participants (24 in FGDs and 10 in KIIs) is shown in Table 1. The highest percentage (41.2\%) was within the range of 30-39 years with the mean age of 32.8 years. Majority (58.8\%) of the participants were married. Most of participants were Protestants (70.6\%), followed by Catholics (23.5\%) and the least were Muslims (5.9\%).

\section{Awareness and perceptions of condom use}

Some participants believed that condoms are safe and effective in preventing HIV infection and re-infection. They also indicated

\begin{tabular}{|l|c|c|}
\hline Socio-demographic characteristics & Frequency (n) & Percent (\%) \\
\hline \begin{tabular}{l|c|} 
Mean age (SD)=32.825 \\
\hline Age in years
\end{tabular} \\
\hline $18-29$ & 13 & 38.2 \\
\hline $30-39$ & 14 & 41.2 \\
\hline $40-49$ & 7 & 20.6 \\
\hline Residence & 28 & 82.4 \\
\hline Thika & 6 & 17.6 \\
\hline Outside Thika & 10 & 29.4 \\
\hline Marital status & 20 & 58.8 \\
\hline Single & 4 & 11.8 \\
\hline Married & & \\
\hline Divorced/widowed & 24 & 70.6 \\
\hline Religion & 8 & 23.5 \\
\hline Christian Protestant & 2 & 5.9 \\
\hline Christian Catholic & & \\
\hline Muslim & & \\
\hline
\end{tabular}

Table 1: Socio-demographic characteristics.

that they were aware of existence of the female condoms. These were pointed out in the following quotes;

"Condoms protect us from acquiring other strains of HIV from infected partners and hence the CD4 counts remain high". (FGD 3)

"We have been showed a female condom during our clinics and how to wear it although most of us opt for the male condom as it is always available and comfortable to use". (FGD 1 and 2)

"Condom use should be emphasized as it is the single most channel for prevention of spread of HIV...it is hard to make people abstain". (FGD 3)

"The staff at the CCC are very helpful and kind; we are counseled during our return clinics, they take time to address our concerns and there is a toll-free line where we can call for any enquiries". (FGD 2)

However, some other study participants indicate that condoms are not $100 \%$ safe and sometimes they break and also they perceive that condoms have pores. These negative beliefs and misconceptions could be associated with non-condom use. Other studies have revealed that women with negative attitude to condom use reduces safe sexual practices [21,22].

"Condoms are not always 100\% safe; some are of poor quality with aeration pores and tend to easily break". (1DI 4)

Cultural misconceptions or inaccurate beliefs may impair use of condoms. The popular belief that latex condoms have pores is erroneous [23]. The source of these beliefs was unclear but health professionals should be aware of these potential barriers to the use of condoms.

It was also indicated that women still feel shy and embarrassed to openly buy condoms from chemists especially from public facilities. It was emphasized that the inaccessibility or unavailability condoms especially in remote areas were the main factors affecting the use of condoms. These were stated as follows:

"Women unlike men do not go buying or carrying condoms in their pockets or bags...if seen people might think we are whores". (FGD 2)

"Sometimes the condoms we get from the clinic don't sustain us until the next visit and we are forced to buy or engage without, especially when my husband claims he forgot to buy or were out of stock". (FGD1 and 3) 
"It is shameful to ask for so many condoms from the clinic and sometimes we run out of them and the clinic is quite distant hence have to wait for the clinic day". (FGD 1)

In this study religion was a main obstacle for using condoms as it is believed to be illegal especially among Catholics. This was consistent with a study conducted in Uganda which found that religion was a significant factor influencing condom use [24]. It was quoted as follows:

"Our religion does not allow use of condoms, although with time this has changed". (IDI 8)

The source of these beliefs was unclear but health professionals should be aware of these potential barriers to the consistent use of condoms. These misconceptions should be considered in efforts to improve consistent condom use among HIV positive women.

\section{Spoiling of pleasure and satisfaction}

Participants of the study pointed out that sexual pleasure is reduced when using condom which is in line with the study conducted in Dare salaam, Tanzania which indicated that condom use was significantly less among respondents who perceived reduced sexual pleasure when using condoms [25]. Sexual pleasure and satisfaction are paramount and the need for immediate sexual gratification may overshadow the use of a condom. Similar findings have been reported among PLWHA in Uganda [26] and the general population in Kenya [27].

"There is lack of sensation and pleasure when using condoms...Our partners don't want to use condoms because they say that they don't feel the sexual pleasure (FGD 3)

\section{Mistrust and lack of negotiation}

Participants reported that refusal to have sex could result in the male partner's seeking sex elsewhere. They commented that the male partner had a strong influence on condom use. The male partner's attitude toward condom use was generally considered negative. It has been indicated that unprotected intercourse among HIV positive women, could be linked to lack of personal control over male partner's use of condoms, less assertiveness and partner's desire to have children [28]. This situation was also reported in this study as the following quotes:

It is impossible to deny partner sex because it is essential for a relationship and if you don't allow it a man will go out and you will be left... and it will be your fault". (IDI 1)

"I know I have to take charge and use condoms. But it is hard convincing him...sometimes he gets to hollering and screaming... What can I do?"(IDI 5)

It was reported that participants find difficult to negotiate with their male partners' especially those who are married. Male partners may resist use of condoms in marital and steady relationships because sex ought to be natural. This attitude has previously been described in studies conducted both in young and older women [29] and underlines the difficulty for women with HIV to negotiate safer sex practices. Therefore, trust and negotiation for condom use should be addressed in educational programs during counseling.

"It is not practical to always negotiate use of condom, it's not like you plan to have sex. Furthermore, we are married". (IDI 10)

Women request for men to use condoms sometimes sparked anger that led men withholding economic support, as well as verbal and physical abuse. Gender inequality has been reported to be a barrier to condom use in many studies [30]. For example in Uganda it was indicated that females had little or no negotiation power in using condoms [31]. However, some of the participants disapproved the statement that only men decide whether to use condoms during sexual encounter:

"Sex is mutual between partners so should the decision to use a condom...We argue about condoms all the time but since I know the consequences for failure to use, I have to ensure he wears". (IDI 9)

It was also noted that, with empowerment, women have become assertive with regard to condom use and disapproving the perception that they have limited control over their male partner.

"I cannot offer him (sex) if he does not want to wear because I now know better, let him say or think what he wants but I won't let him ruin my life"...(IDI 10)

\section{Non-disclosure of HIV positive status}

Non-disclosure of HIV status is the main hindrance to condom use. Therefore, public awareness campaigns should be mounted through programs to focus on interventions to increase condom use among HIV positive women with emphasis on need for disclosure.

"We rarely use condom because my husband does not know my HIV status and he has refused to go for testing with me...I cannot disclose to him because he might blame me and then leave me, so we rarely use condom". (IDI 6)

Unprotected sex with HIV positive is high risk sexual behaviour for HIV transmission and a major public health issue [32]. It is found that $50 \%-70 \%$ of seroconcordant, serodiscordant, and unknown status couples reported unprotected sex with their partners [33]. Not disclosing one's HIV status to a sexual partner increases the risk of having unprotected sex among HIV positive people [34]. Knowledge of partner's HIV status contributes to condom use among HIV positives, which subsequently reduces HIV infection $[35,36]$.

\section{Partner's alcohol consumption/use}

Alcohol use by the male partners was significant cause of barrier in condom use. Alcohol use has been linked to HIV-1 risk in previous studies as well [29,37-39].

"Sometimes my partner comes home drank and is very difficult to discuss condom use...he even gets violent when I deny him". (IDI 8)

So efforts should be strengthened towards reduction of alcohol use among HIV positive women.

\section{Conclusion and Recommendations}

In conclusion, our findings reflect multifactorial barriers for condom use among HIV-positive women. The major hindrances to use condom mentioned by the participants were inability to negotiate condom use, fear of mistrust, non-disclosure of HIV positive status to partner, alcohol use, and reduced sexual pleasure. Moreover, among the negative beliefs and misconceptions identified as barriers of condom use were feeling promiscuous for carrying condoms, religion being Catholics and thinking condoms have pores. Therefore, ministry of health and other concerned stakeholders should continually educate HIV positive women and their partners to increase awareness on the importance of consistent condom use during counseling at the comprehensive care center. More specifically efforts should be strengthened towards empowering women to negotiate condom use, towards educational programs on fear of mistrust and non-disclosure, towards reduction of alcohol use, and towards increasing access to 
Citation: Macharia AG, Kombe Y, Mwaniki P, Habtu M (2017) Barriers of Condom Use among HIV Positive Women at Thika Level 5 Hospital, Kenya. J AIDS Clin Res 8: 722. doi: 10.4172/2155-6113.1000722

Page 4 of 4

information on negative beliefs and misconceptions especially among Catholic followers.

\section{Acknowledgement}

The authors acknowledge to all women who participated in this study for their time and willingness. The authors also give special thanks to the manager and all staff members of Comprehensive Care Centre of Thika Level 5 Hospital for their cooperation during the collection of data for this study and allowing us to conduct this research.

\section{References}

1. UNAIDS (2013) Global report: UNAIDS report on the global AIDS epidemic 2013. UNAIDS 198.

2. UNAIDS (2011) Global HIVIAIDS response: Epidemic update and health sector progress towards Universal Access Progress Report 2011. WHO, Geneva, Switzerland.

3. UNAIDS (2015) HIV and AIDS estimates.

4. Kenya National AIDS Control Council (2014) Kenya AIDS Strategic Framework 2014/2015-2018/2019.

5. Mayer KH, Venkatesh KK (2010) Antiretroviral therapy as HIV prevention: Status and prospects. Am J Public Health 100: 1867-1876.

6. Crum NF, Riffenburgh RH, Wegner S, Agan BK, Tasker SA, et al. (2006) Comparisons of causes of death and mortality rates among HIV-infected persons: analysis of the pre-, early and late HAART (highly active antiretroviral therapy) eras. J Acquir Immune Defic Syndr 41: 194-200.

7. Boily MC, Godin G, Hogben M, Sherr L, Bastos FI (2005) The impact of the transmission dynamics of the HIVIAIDS epidemic on sexual behaviour: A new hypothesis to explain recent increases in risk taking-behaviour among men who have sex with men. Med Hypotheses 65: 215-226.

8. Donnell D, Baeten JM, Kiarie J, Thomas KK, Stevens W, et al. (2010) Heterosexual HIV-1 transmission after initiation of antiretroviral therapy: A prospective cohort analysis. Lancet 375: 2092-2098.

9. Anglemyer A, Rutherford GW, Baggaley RC, Egger M, Siegfried N (2011) Antiretroviral therapy for prevention of HIV transmission in HIV-discordant couples. Cochrane Database Syst Rev CD009153.

10. Cohen MS, Chen YQ, McCauley M, Gamble T, Hosseinipour MC, et al. (2011) Prevention of HIV-1 infection with early antiretroviral therapy. N Engl J Med 365: 493-505.

11. Centers for Disease Control and Prevention (2008) CDC underscores current recommendation for preventing HIV transmission.

12. Filder S, Anderson J, Azad Y, Delpech V, Evans C, et al. (2013) Position statement on the use of antiretroviral therapy to reduce HIV transmission, January 2013: The British HIV Association (BHIVA) and the Expert Advisory Group on AIDS (EAGA). HIV Medicine 14: 259-262.

13. De Cock KM, Gilks CF, Lo YR, Guerma T (2009) Can antiretroviral therapy eliminate HIV transmission? Lancet 373: 7-9

14. Cohen MS, Gay C, Kashuba AD, Blower S, Paxton L (2007) Narrative review: Antiretroviral therapy to prevent the sexual transmission of HIV-1. Ann Intern Med 146: 591-601.

15. Coates TJ, Richter L, Caceres C (2008) Behavioural strategies to reduce HIV transmission: How to make them work better. Lancet 372: 669-684.

16. Philpott A, Knerr W, Boydell V (2006) Pleasure and prevention: When good sex is safer sex. Reprod Health Matters 14: 23-31.

17. Sarna A, Luchters S, Geibel S, Kaai S, Munyao P, et al. (2008) Sexual risk behaviour and HAART: A comparative study of HIV-Infected persons on HAART and on preventive therapy in Kenya. Int J STD AIDS 19: 85-89.

18. Yalew E, Zegeye DT, Meseret S (2012) Patterns of condom use and associated factors among adult HIV positive clients in North Western Ethiopia: A Comparative cross sectional study. BMC Public Health 12: 308.
19. Auerbach JD (2004) Principles of positive prevention. J Acquir Immune Defic Syndr 37: S122-S125.

20. Crepaz N, Lyles CM, Wolitski RJ, Passin WF, Rama SM, et al. (2006) Do prevention interventions reduce HIV risk behaviours among people living with HIV? A meta-analytic review of controlled trials. AIDS 20: 143-157.

21. Awusabo-Asare K, Anarfi JK, Agyeman DK (1993) Women's control over their sexuality and the spread of STDs and HIVIAIDS in Ghana. Health Transition Review 3: 69-83.

22. Dixon-Mueller R (1993) The sexuality connection in reproductive health. Stud Fam Plann 24: 269-282.

23. Centre for Disease Control (1992) HIVIAIDS prevention: Training Bulletin. CDC

24. Kinsman J, Nakiyingi J, Kamali A, Whitworth J (2001) Condom awareness and intended use: Gender and religious contrasts among school pupils in rural Masaka, Uganda. AIDS Care 13: 215-220.

25. Katikiro E, Njau B (2012) Motivating factors and psychosocial barriers to condom use among out-of-school youths in Dar es Salaam, Tanzania: A cross sectional survey using the health belief model. ISRN AIDS 2012: 170739.

26. Allen C, Mbonye M, Seeley J, Birungi J, Wolff B, et al. (2011) ABC for people with HIV: Responses to sexual behaviour recommendations among people receiving antiretroviral therapy in Jinja, Uganda. Cult Health Sex 13: 529-543.

27. Thomsen S, Stalker M, Toroitich-Ruto C (2004) Fifty ways to leave your rubber: How men in Mombasa rationalise unsafe sex. Sex Transm Infect 80: 430-434.

28. Crepaz N, Hart TA, Marks G (2004) Highly active antiretroviral therapy and sexual risk behavior: A meta-analytic review. J Am Med Assoc 292: 224-236.

29. Sarkar NN (2008) Barriers to condom use. Eur J Contracept Reprod Health Care 13: 114-122.

30. Van Devanter N, Duncan A, Birnbaum J, Burrell-Piggott T, Siegel K (2011) Gender power inequality and continued sexual risk behavior among racial/ ethnic minority adolescent and young adult women living with HIV. J AIDS Clin Res, pp: 83-93.

31. Kibombo R, Neema S, Moore AM, Ahmed FH (2008) Adults' perceptions of adolescents' sexual and reproductive health: Qualitative evidence from Uganda. Guttmacher Institute, New York, NY.

32. Dessie Y, Gerbaba M, Bedru A, Davey G (2011) Risky sexual practices and related factors among ART attendees in Addis Ababa public hospitals, Ethiopia: A cross-sectional study. BMC Public Health 11: 422.

33. Wagner GJ, Holloway I, Ghosh-Dastidar B, Ryan G, Kityo C, et al. (2010) Factors associated with condom use among HIV clients in stable relationships with partners at varying risk for HIV in Uganda. AIDS Behav 14: 1055-1065.

34. Mlambo M, Peltzer K (2011) HIV sero-status disclosure and sexual behaviour among HIV positive patients who are on Antiretroviral Treatment (ART) in Mpumalanga, South Africa. J Hum Ecol 35: 29-41.

35. Wagner GJ, Holloway I, Ghosh-Dastidar B, Ryan G, Kityo C, et al. (2010) Factors associated with condom use among HIV clients in stable relationship with partners at varying risk for HIV in Uganda. AIDS Behav 14: 1055-1065.

36. Conserve D, Sevilla L, Younge S, Mbwambo J, King G (2012) Condom use among HIV-positive sexually active adults and partner's HIV status in Dar es Salaam, Tanzania. J Health Care Poor Underserved 23: 191-203.

37. Chakrapani V, Newman PA, Shunmugam M, Dubrow R (2010) Prevalence and contexts of inconsistent condom use among heterosexual men and women living with HIV-1 in India: Implications for prevention. AIDS Patient Care STDS 24: 49-58.

38. Chersich MF, Rees HV, Scorgie F, Martin G (2009) Enhancing global control of alcohol to reduce unsafe sex and HIV-1 in sub-Saharan Africa. Global Health 5: 16 .

39. Kalichman SC, Simbayi LC, Kaufman M, Cain D, Jooste S (2007) Alcohol use and sexual risks for HIV-1/AIDS in sub-Saharan Africa: Systematic review of empirical findings. Prev Sci 8: 141-151. 